\title{
Article \\ Superhydrophobic Ni-Reduced Graphene Oxide Hybrid Coatings with Quasi-Periodic Spike Structures
}

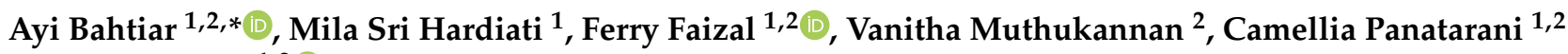 \\ and I Made Joni ${ }^{1,2}$ (D)
}

Citation: Bahtiar, A.; Hardiati, M.S.; Faizal, F.; Muthukannan, V.; Panatarani, C.; Joni, I.M. Superhydrophobic Ni-Reduced Graphene Oxide Hybrid Coatings with Quasi-Periodic Spike Structures. Nanomaterials 2022, 12, 314. https:// doi.org/10.3390/nano12030314

Academic Editor: Sergei Kulinich

Received: 27 December 2021

Accepted: 18 January 2022

Published: 19 January 2022

Publisher's Note: MDPI stays neutral with regard to jurisdictional claims in published maps and institutional affiliations.

Copyright: (C) 2022 by the authors. Licensee MDPI, Basel, Switzerland. This article is an open access article distributed under the terms and conditions of the Creative Commons Attribution (CC BY) license (https:// creativecommons.org/licenses/by/ $4.0 /)$.
1 Department of Physics, Faculty of Mathematics and Natural Sciences, Universitas Padjadjaran, Jalan Raya Bandung-Sumedang KM 21, Jatinangor, Sumedang 45363, West Java, Indonesia; mila.srihardiati@gmail.com (M.S.H.); ferry.faizal@unpad.ac.id (F.F.); c.panatarani@phys.unpad.ac.id (C.P.); imadejoni@phys.unpad.ac.id (I.M.J.)

2 Functional Nano Powder University Center of Excellence (FiNder U CoE), Universitas Padjadjaran, Jalan Raya Bandung-Sumedang KM 21, Jatinangor, Sumedang 45363, West Java, Indonesia; vanithachel@gmail.com

* Correspondence: ayi.bahtiar@phys.unpad.ac.id; Tel.: +62-81394820773

\begin{abstract}
Recently, sophisticated technologies are applied to design a certain surface nature that can have superhydrophobic properties. Thus, a simple spray technique was introduced to prepare a superhydrophobic surface using rGO with $\mathrm{Ni}-\mathrm{S}$ system (rGO-Ni) by using $\mathrm{NiSO}_{4}$ catalyst under microwave irradiation at various reaction times of 5, 10, 20, and $30 \mathrm{~min}$. The GO reduction was conducted at a fixed $\mathrm{Ar} / \mathrm{H}_{2}$ ratio, a flow rate of $0.4 \mathrm{~L} / \mathrm{min}$, microwave power of $720 \mathrm{~W}$, and a mass of $0.5 \mathrm{~g}$. GO powder with nickel sulfate catalyst was treated under $\mathrm{Ar} / \mathrm{H}_{2}$ (4:1) mixture for GO reduction, where $\mathrm{Ar}$ and $\mathrm{H}_{2}$ were expected to prevent the rebinding of oxygen released from GO. The result of XRD and Raman measurement confirms that rGO-Ni prepared at reaction time $20 \mathrm{~min}$ exhibit the highest reduction of GO and the presence of various Ni-S crystal structures such as NiS, $\mathrm{NiS}_{2}, \mathrm{Ni}_{3} \mathrm{~S}_{2}$, and $\mathrm{Ni}_{3} \mathrm{~S}_{4}$ due to decomposition of $\mathrm{NiSO}_{4}$. The rGO-Ni coating performance shows superhydrophobic nature with a contact angle of $150.1^{\circ}$. The AFM images show that the addition of nickel to rGO produces a quasi-periodic spike structure, which increases the superhydrophobicity of the r-GO-Ni coated glass with a contact angle of $152.6^{\circ}$. It is emphasized that the proposed simple spray coating using rGO-Ni provides a more favorable option for industry application in obtaining superhydrophobic surfaces.
\end{abstract}

Keywords: reduced graphene oxide; Ni-reduced graphene oxide; graphene; oxidation; microwave; superhydrophobic

\section{Introduction}

Graphene and its derivative compounds such as graphene oxide (GO) and reduced graphene oxide ( $\mathrm{rGO}$ ) recently have become promising materials that are entitled to be developed because of their properties, such as high electrical conductivity, thermal conductivity, surface area, and tensile strength [1-4]. These properties enable graphene to be used for various applications such as photovoltaic cells, sensors, chemical energy storage devices, transistors, transparent electrodes, and coatings. Graphene and graphene-related materials have become increasing research interests due to many remarkable features that make them suitable for a passive-layer formation that protects metals from oxidation and corrosion [5-8]. Graphene and its related materials can also be applied as coating glass for self-cleaning glass that causes a superhydrophobic surface of the glass $[9,10]$. A superhydrophobic surface can be characterized by its water contact angle in the range of $150^{\circ}<\theta<180^{\circ}$; therefore, water droplets can roll on the surface and take away the dirt sticking on the surface effectively.

Graphene can be produced by exfoliation of graphite, epitaxial growth, chemical vapor deposition (CVD), and reduction of graphene oxide [11,12]. The reduction of GO that 
formed reduced graphene oxide $(\mathrm{rGO})$ is the most popular method to produce graphene because of its low production costs and a larger quantity of the material compared to other methods [11]. Graphene oxide is the exfoliated graphite that is treated in an oxygen-rich environment and oxidized to intersperse the carbon layers with oxygen molecules that have reactive functional groups such as hydroxyl, epoxy, and carboxyl groups [3,12,13]. GO is reduced by various methods to separate layers of carbon into a material that resembles graphene called rGO [13].

Thermal reduction is one of the reduction methods that is often used by carrying out the reaction at high temperatures that reach above $2000{ }^{\circ} \mathrm{C}$ [14-16]. As an alternative, Zou et al. (2003) [17] and Chu and $\mathrm{Li}$ (2006) [18] have tried to use several unconventional heating sources to reduce temperatures, including microwave irradiation (MWI). The main advantage of microwave irradiation over conventional heating methods is that heating occurs uniformly and rapidly. Reduced graphene oxide (rGO) can be easily obtained within one minute by treatment under microwave irradiation. Aside from temperature, the heating atmosphere is also important for the reduction process of GO, and oxygen increases dramatically at high temperatures. Therefore, oxygen must be released during heating. Thermal reduction is usually carried out in a vacuum, an inert atmosphere, or in presence of reducing gases. Argon (Ar), known as an inert gas, can prevent released oxygen back to the material. Reducing gases such as hydrogen $\left(\mathrm{H}_{2}\right)$ can react with the remaining oxygen in the atmosphere, and they flow along with the gas flow. The ability of $\mathrm{H}_{2}$ to reduce $\mathrm{O}_{2}$ is adequate to make the reduction of GO and can be finished at relatively low temperatures in the $\mathrm{H}_{2}$ atmosphere [11].

Khai et al. (2013) [19] warmed GO sheets at a high temperature of $1100{ }^{\circ} \mathrm{C}$ for $30 \mathrm{~min}$ on a system with gas $\left(\mathrm{Ar}+\mathrm{H}_{2}\right)$ flowing at a constant speed of $100 \mathrm{sccm}$, to reduce humidity and temperature of the system. Chen et al. (2010) [20] also reduced GO by microwave hydrothermal with a mixture of $\mathrm{N}, \mathrm{N}$-dimethylacetamide, and water. The power of the microwave is $800 \mathrm{~W}$, and $\mathrm{rGO}$ with a conductivity of $200 \mathrm{~S} / \mathrm{m}$ is produced in a few minutes. Recently, we have successfully synthesized rGO by microwave-assisted methods within the $\mathrm{Ar} / \mathrm{H}_{2}$ gas flow rate of $0.4 \mathrm{~L} / \mathrm{min}$ and microwave power of 720 Watt provide optimum oxygen group reduction [21].

Superhydrophobic surfaces with water contact angles (CA) $>150^{\circ}$ have increased attention due to their numerous potential applications such as anti-icing, self-cleaning, oil-water separation, and anticorrosion [22-24]. Reduced graphene oxide (rGO) is a suitable candidate as superhydrophobic material, due to its hydrophobicity in nature, its large specific surface area, abrasion resistance, and excellent conductivity. Various methods such as sol-gel, 3D printing, chemical etching, chemical vapor deposition, electrospinning, chemical bath deposition, polymer grafting, and self-assembly have been used to prepare superhydrophobic surfaces $[25,26]$. Another group also reports on the engineering of the material to improve the hydrophobicity of the surface such as using polydimethylsiloxane as a transparent agent [27]. However, most of these methods are not favorable for industrial application due to their complexity and time-consuming procedures. Finding a simple method for producing superhydrophobic surfaces is, therefore, highly needed for large-scale applications. Recently, Esmailzadeh et al. used the electrodeposition technique to prepare a thin nickel layer consisting of micro-cones structure on a copper substrate, producing a superhydrophobic surface with water CA of $155^{\circ}$ [28]. The composite of rGO and nickel, therefore, can be very interesting to be studied for preparing superhydrophobic surfaces with a high value of CA. Ding et al. prepared a superhydrophobic rGO/Ni composite coating on mild steel with water CA $160.4^{\circ}$ using the electrodeposition technique [29]. However, the substrate could not be covered completely by the $\mathrm{rGO} /$ nickel composite particles after the deposition process. Recently, Bai and Zhang prepared a novel rGO/Ni composite coating with pinecone-like micro/nanostructures on a stainless steel substrate using an electrodeposition method combining Ni pre-deposition and an elevated current assistant approach [30]. The coating showed a self-cleaning effect and superhydrophobicity, with a CA of $162.7^{\circ}$. Another report by Schneider et al. showed that a regular micro- and 
nanocone structure induce superhydrophobicity of the surface [31]. Therefore, producing periodic micro- and nanostructure or spike structures on the coated surface will produce a superhydrophobic layer with a high value of CA.

Therefore, the aims of the present study are to study the properties of rGO and rGO with Ni-S system using $\mathrm{NiSO}_{4}$ catalyst (rGO-Ni) and evaluate their hydrophobicity performance of a composite coating in comparison with graphite and without any filler. The spray technique on the preparation of superhydrophobic surface with rGO-Ni composite is a novel approach to provide more favorable for industry, compared with other sophisticated available techniques to the engineering of the surface morphology. In this study, we prepared an rGO-Ni coated layer from GO reduction synthesized by the microwave-assisted method under the mixture of $\mathrm{Ar}$ and $\mathrm{H}_{2}$ gases at various reaction times.

\section{Materials and Methods}

\subsection{Preparation of Graphene Oxide}

The chemicals used in the preparation of graphene oxide were graphite (Merck), sodium nitrate $\left(\mathrm{NaNO}_{3}\right)$, sulfuric acid $\left(\mathrm{H}_{2} \mathrm{SO}_{4}\right)$, potassium permanganate $\left(\mathrm{KMnO}_{4}\right)$, concentrated hydrochloric acid $(\mathrm{HCl})$, and hydrogen peroxide $\left(\mathrm{H}_{2} \mathrm{O}_{2}\right)$. The graphite was purchased from Merck Chemicals, Jakarta, Indonesia, and the graphene oxide (GO) was prepared following the modified Hummers method [32]. Two grams of graphite powder and one gram of sodium nitrate were mixed in $45 \mathrm{~mL}$ of sulfuric acid, and the mixture was continuously stirred in an Erlenmeyer flask stored within the ice bath $\left(0-5^{\circ} \mathrm{C}\right)$ for $30 \mathrm{~min}$. Then, five grams of potassium permanganate was prepared and added to the mixture by a small amount stepwise. The precaution was necessary when introducing the potassium permanganate to maintain a temperature less than $20^{\circ} \mathrm{C}$. The mixture was stirred once more for 30; then, the ice bath was substituted with a silicon oil bath. The sample was stirred at $35^{\circ} \mathrm{C}$ for one hour. The mixture was then subjected to dilution with slowly added $45 \mathrm{~mL}$ of distilled water. Consequently, the temperature rapidly rose to $98^{\circ} \mathrm{C}$ while keeping stirring for another $40 \mathrm{~min}$. Additional dilution was carried out for $200 \mathrm{~mL}$ of distilled water and $25 \mathrm{~mL}$ of hydrogen peroxide while keeping stirring for $30 \mathrm{~min}$. Finally, $10 \mathrm{~mL}$ of $\mathrm{HCl}$ solution in deionized water was used to clean the sample and continuously washed several times with distilled water. The sample was centrifuged to separate the substances. $\mathrm{GO}$ was dried in a drying cabinet to obtain the GO powder.

\subsection{Mixing with Nickel Sulfate}

An experiment by Joni et al. (2008) [33] shows that GO synthesized from graphitization with a nickel sulfate catalyst is better than GO synthesized from commercial graphite. Therefore, in this experiment, GO powder was mixed with nickel sulfate. The procedure for mixing GO with $\mathrm{NiSO}_{4}$ catalyst was obtained by dissolving $1.578 \mathrm{~g}$ of $\mathrm{NiSO}_{4}$ with $10 \mathrm{~mL}$ of distilled water and stirring for $1 \mathrm{~h}$ until completely dissolved. Then, one gram of GO was added into the $\mathrm{NiSO}_{4}$ solution and stirred for $4 \mathrm{~h}$. The residue was filtered and dried in an oven for $5 \mathrm{~h}$ at $65-70{ }^{\circ} \mathrm{C}$ [33]. After the drying process, GO powder with a $\mathrm{NiSO}_{4}$ catalyst was produced. This GO sample was then subjected to a reduction process using microwave irradiation.

\subsection{Reduction of GO}

The GO reduction process was carried out using the microwave irradiation method, with equipment arranged as shown in Figure 1, referring to the best-optimized reduction process from our previous study [21]. The sample with a mass of $0.5 \mathrm{~g}$ was added into the separate glass, which was tightly closed and kept in the microwave oven. $\mathrm{Ar} / \mathrm{H}_{2}$ gas mixture was passed through the glass by means of the inlet pipe and exited through the outlet pipe with a flow rate of $0.4 \mathrm{~L} / \mathrm{min}$. An indication of gas discharge is the presence of air bubbles in the water placed on a beaker. Furthermore, the microwave oven was turned on, by setting the power of $720 \mathrm{~W}$ [34]. The reduction process was conducted in various reaction times $1,5,10,20$, and $30 \mathrm{~min}$. 


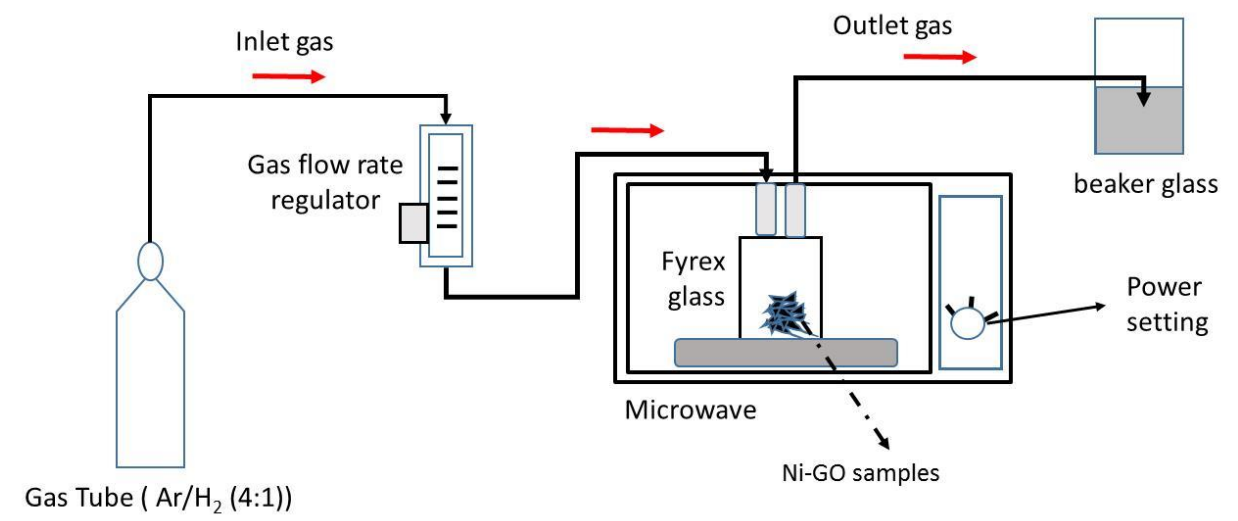

Figure 1. Schematic experimental setup of GO microwave irradiation.

\subsection{Preparation of GO Layer}

For this step, $0.1 \mathrm{~g}(5 \%) \mathrm{GO}$ was added into $1.3 \mathrm{~g}(65 \%)$ thinner solution (mixing of butyl acetate (BA) and xylene with ratio 1:1) and then stirred for $30 \mathrm{~min}$. Afterward, $0.6 \mathrm{~g}$ $(30 \%)$ of binder (TPA resin) was added to the solution and was stirred for $30 \mathrm{~min}$. The GO layer was prepared by spraying the solution onto the preparatory glass using a Meiji air paintbrush with a distance of about $30 \mathrm{~cm}$ from the surface of the glass. Then, it was dried in an oven at $350^{\circ} \mathrm{C}$ for $30 \mathrm{~min}$. A similar procedure was carried out for the preparation of graphite, rGO, and rGO-Ni layers. For contact angle testing, $5 \mu \mathrm{L}$ of deionized water solution was dropped onto the layers. A glass coated by paint was used as a control for the comparison of contact angle testing and AFM measurement.

\subsection{Characterization}

The synthesized GO by modified Hummer's method, as well as rGO and rGO-Ni by microwave irradiation methods, were characterized by Fourier-transform infrared spectroscopy (FTIR, Nicolet Is5 Thermo, Toronto, ON, Canada), X-ray diffraction analysis (XRD, PANalytical X'Pert PRO PW3040/x0, Almelo, Netherlands), scanning electron spectroscopy-energy dispersive spectrometer (SEM-EDS, SU3500 Hitachi -EDAX TEAM, Tokyo, Japan), Raman spectroscopy (XploRA ${ }^{\mathrm{TM}}$ PLUS - HORIBA, Kyoto, Japan) contact angle testing (laboratorymade), and atomic force microscopy (AFM, Park System XE 100, Suwon, Korea).

\section{Results and Discussion}

\subsection{FTIR Analysis}

FTIR spectra of GO before and after mixing with the $\mathrm{NiSO}_{4}$ catalyst or GO-Ni and rGO-Ni prepared with $0.5 \mathrm{~g} \mathrm{GO}$, flowrate $0.4 \mathrm{~L} / \mathrm{min}$, microwave power of $720 \mathrm{~W}$, and one-minute reaction are shown in Figure 2a. The peak at 1060 and at $1625 \mathrm{~cm}^{-1}$ are correspondingly identified as $\mathrm{C}-\mathrm{O}$ and $\mathrm{C}=\mathrm{C}$ bonds. The $\mathrm{C}-\mathrm{O}$ bond indicated the existence of oxygen functional groups on the surface of $\mathrm{GO}$. The $\mathrm{C}=\mathrm{C}$ function group is the elementary structure of GO or rGO, which is bound together and forms a hexagonal structure where the double bond is a covalent bond formed from $\mathrm{sp}^{3}$ hybridization into $\mathrm{sp}^{2}$ and is difficult to be disrupted because of its higher bond energy. A peak at $1720 \mathrm{~cm}^{-1}$ in the GO spectrum relates to the $\mathrm{C}=\mathrm{O}$ bonds. A broad peak is observed around $2900-3650 \mathrm{~cm}^{-1}$ due to the $\mathrm{O}-\mathrm{H}$ stretching of the $\mathrm{H}_{2} \mathrm{O}$ molecule. The spectra assigned for oxygen groups in $\mathrm{GO}-\mathrm{Ni}$ show more visibly than $\mathrm{GO}$ due to the enhanced oxidation process by $\mathrm{NiSO}_{4}$ catalyst on the surface of the synthesized GO. The spectrum of rGO-Ni shows oxygen-containing groups, i.e., $\mathrm{OH}$ and $\mathrm{C}=\mathrm{O}$ lines are decreased, compared with $\mathrm{GO}$, which indicated that the oxygen-containing group was reduced. This indicated that our proposed microwave irradiation methods for the mixture of $\mathrm{GO}$ and $\mathrm{NiSO}_{4}$ successfully reduced the oxygen functional groups [35]. 


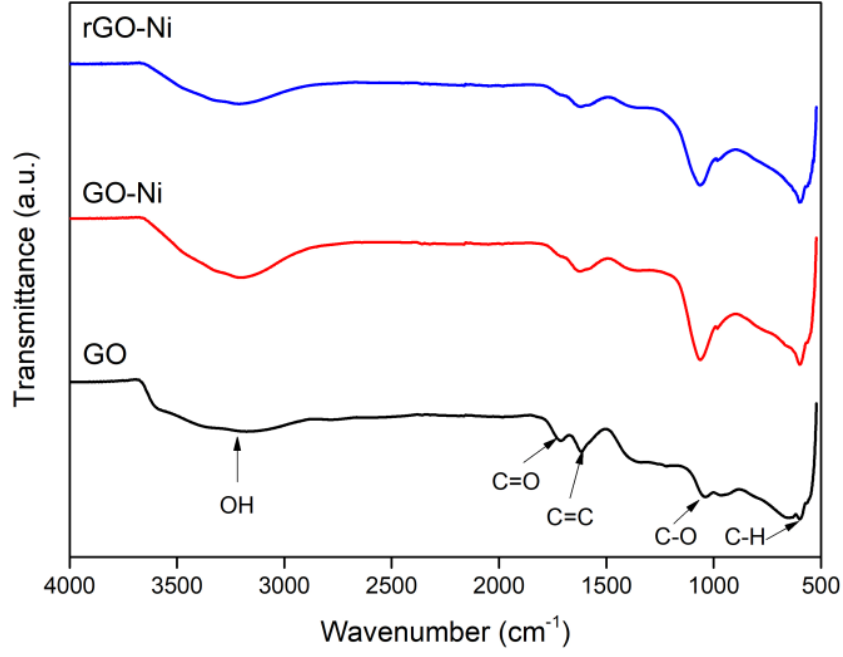

(a)

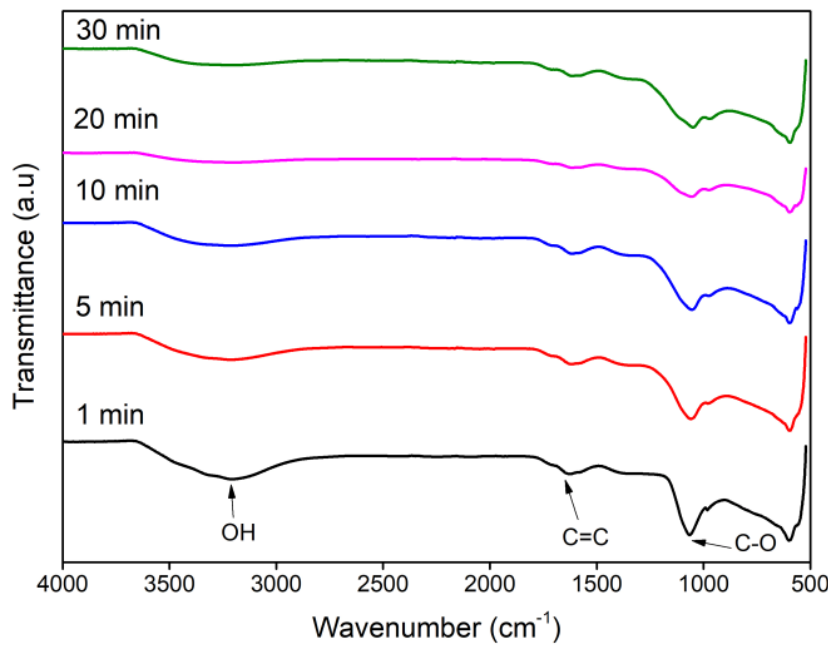

(b)

Figure 2. The FTIR spectra of (a) GO and GO-Ni and $\mathrm{rGO}-\mathrm{Ni}$ prepared with $0.5 \mathrm{~g}$ GO at gas flow rate $0.4 \mathrm{~L} / \mathrm{min}$, one minute reaction time, and with a microwave power of $720 \mathrm{~W}$ and (b) $\mathrm{rGO}-\mathrm{Ni}$ prepared at $720 \mathrm{~W}$ with a variation of reaction times.

In order to find the optimum reaction time, the reaction times were varied for $5 \mathrm{~min}$, $10 \mathrm{~min}, 20 \mathrm{~min}$, and $30 \mathrm{~min}$, with fixed parameters of mass of $0.5 \mathrm{~g}$, a gas flow rate of $0.4 \mathrm{~L} / \mathrm{min}$, and microwave power of $80 \mathrm{P}(720 \mathrm{~W})$. FTIR results from time variation experiments can be seen in Figure 2b, which shows a significant difference. It can be seen that at the time of $20 \mathrm{~min}$, the peaks of the oxygen-containing groups on the $\mathrm{O}-\mathrm{H}$ and $\mathrm{C}=\mathrm{O}$ vary dramatically to resemble almost a straight line. This indicates that the reduction process of $20 \mathrm{~min}$ is the best reaction time because the oxygen-containing groups in the sample have reduced significantly. The graph also shows that the peak for $\mathrm{C}=\mathrm{C}$ at a wavenumber of $1605 \mathrm{~cm}^{-1}$ is still visible. When GO is irradiated by microwave at certain times, the oxygen bond in the GO will be released and turn into ions and subsequently released along with the gas flow. If the irradiation time of GO is prolonged, more oxygen bonds are released. Thus, the success of reduction to prevent oxygen rebinding into GO depends on the ratio of the amount of released oxygen and $\mathrm{H}_{2}$ and expel as $\mathrm{H}_{2} \mathrm{O}$. After reaction times of more than $20 \mathrm{~min}$, the hydrogen gas may react with increasing oxygen released from GO to form $\mathrm{O}-\mathrm{H}$ binding on the GO surface, as shown in Figure $2 \mathrm{~b}(30 \mathrm{~min})$.

\subsection{XRD Analysis}

XRD patterns of graphite, GO, and $\mathrm{rGO}-\mathrm{Ni}$ with various reaction times are shown in Figure 3a. The XRD pattern of pure graphite reveals an intense peak around $26^{\circ}$, which corresponds to the crystal plane (002). The XRD pattern of GO illustrates three peaks at $11^{\circ}, 26^{\circ}$, and $42.5^{\circ}$, corresponding to the peak of the crystal plane (001), (002), and (100), respectively. The diffraction peak at $2 \theta=11^{\circ}$ is caused by graphitic oxidation, according to the GO peak, which shows the intercalation of various functional groups after oxidation of graphite. Graphite was successfully oxidized to GO, which shows a characteristic peak at $2 \theta=11^{\circ}$. The graphite peak still exists at $26^{\circ}$, and the graphite group can be adjusted by varying the concentration of the material used in the oxidation process and obtaining the conversion of graphite to GO completely. The peak at $2 \theta=42.2^{\circ}$ with small intensity originates from a non-oxidized graphitic group [34]. The absence of a peak around 10-11 ${ }^{\circ}$ in the XRD pattern of rGO-Ni confirms the reduction of GO to rGO. 


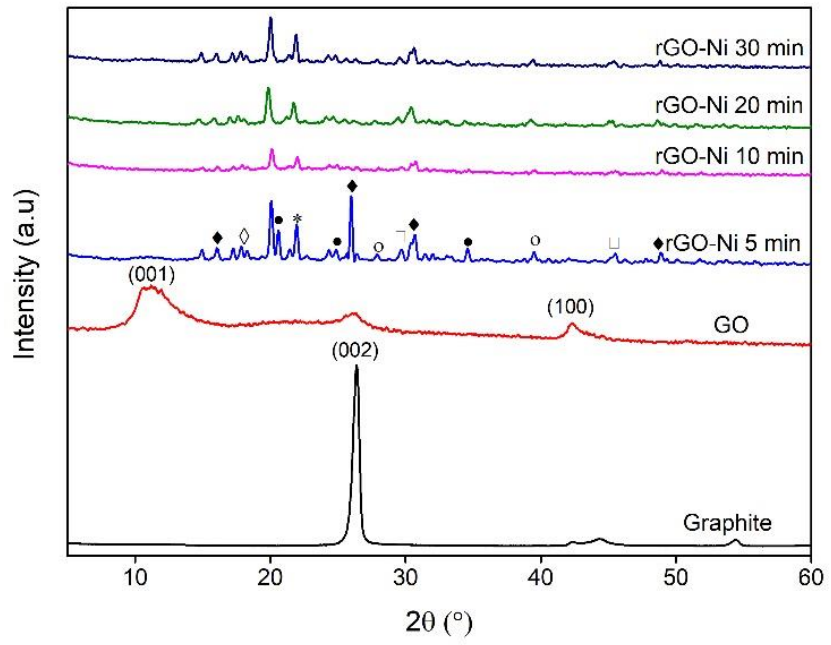

(a)

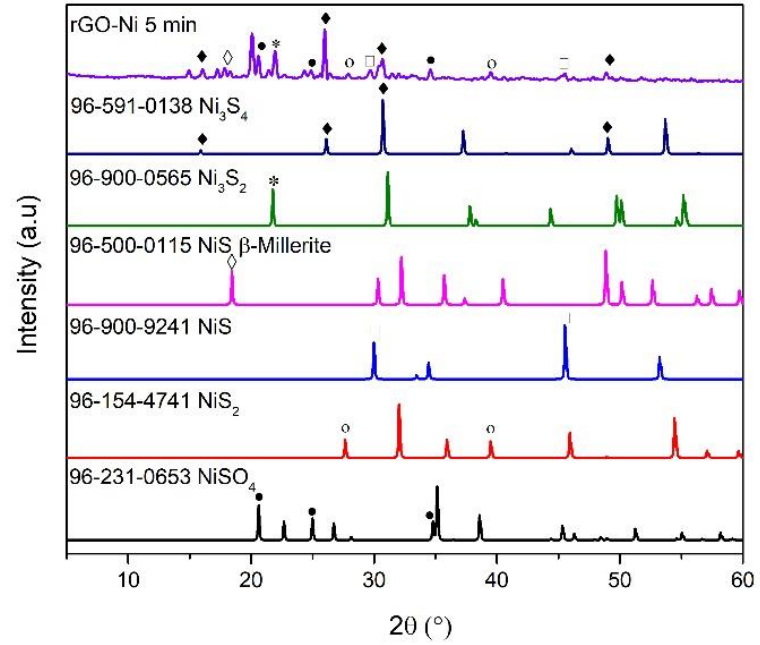

(b)

Figure 3. XRD pattern of (a) graphite, GO, and rGO-Ni with various reaction times, and (b) rGO-Ni with reaction times $5 \mathrm{~min}$ in comparison with various $\mathrm{Ni}-\mathrm{S}$ crystal structures.

The crystal structure of rGO-Ni varies in reaction times of 5, 10, 20, and $30 \mathrm{~min}$ exhibited various Ni-S crystal structures (Figure $3 a$ ). In order to identify the crystal phase transformation during microwave irradiation due to $\mathrm{NiSO}_{4}$ decomposition, the XRD of $\mathrm{r}$-GO-Ni with reaction times $5 \mathrm{~min}$ is compared with possible XRD of the Ni-S system (Figure $3 b$ ). The XRD pattern at a reaction time of 5 min clearly appears to various $\mathrm{Ni}-\mathrm{S}$ crystal structures such as $\mathrm{NiS}, \mathrm{NiS}_{2}, \mathrm{Ni}_{3} \mathrm{~S}_{2}$, and $\mathrm{Ni}_{3} \mathrm{~S}_{4}$ due to the decomposition of $\mathrm{NiSO}_{4}$. The $\mathrm{XRD}$ peak for $\mathrm{NiSO}_{4}$ is vanished, indicating decomposition occurred during microwave irradiation (Figure 3a). At reaction time $5 \mathrm{~min}$, two remarkable XRD peaks at $26^{\circ}$ and $31.7^{\circ}$ are observed, indicating the initial crystal phase formation of $\mathrm{Ni}_{3} \mathrm{~S}_{4}$. After reaction time elapses for 10, 20, and $30 \mathrm{~min}$, the peak at $26^{\circ}$ is disappeared to form a $\mathrm{Ni}_{3} \mathrm{~S}_{4}$ crystal structure. It is observed that all Ni-S systems such as $\mathrm{NiS}, \mathrm{NiS}_{2}, \mathrm{Ni}_{3} \mathrm{~S}_{2}$, and $\mathrm{Ni}_{3} \mathrm{~S}_{4}$ are still present at reaction times 10, 20, and $30 \mathrm{~min}$. In contrast, the highest peak appears at $20^{\circ}$ at reaction times 10,20, and $30 \mathrm{~min}$, representing the crystal system of the rGO decorated N-S system [35].

\subsection{Raman Spectroscopy}

Raman spectroscopy is one of the powerful techniques used to characterize carbonbased materials, as it is non-destructive, fast, and has high resolution. The structural and electronic information of the conjugated and double-bonded carbon-carbon leads to high intense peaks in Raman spectroscopy $[11,19,36]$. Figure 4 shows the Raman shift of graphite, $\mathrm{GO}$, and rGO-Ni with reaction time variation.

Graphite has the $G$ band at $1565 \mathrm{~cm}^{-1}$ and the $D$ band at $1330 \mathrm{~cm}^{-1}$. The $G$ band correlates to the in-phase $\mathrm{C}-\mathrm{C}$ stretching vibration of the graphite, and the $\mathrm{D}$ band represents the disordered band caused by the graphite edges. The $\mathrm{D}$ band is present in all defective graphene samples, and therefore, it is a favorable measure of the quality of the carbon produced. Raman spectra of GO show the G band with decreased intensity caused by the disordered of graphite lattice, which was introduced upon oxidation. The reduction of GO restores the position of the $\mathrm{G}$ band to almost the same position as graphite, indicating a considerable restoration of the graphitic lattice. The overall intensity of Raman spectra increases after the reduction treatment, which substantiates the increased carbon-to-oxygen ratio, owing to the $\mathrm{NiSO}_{4}$ catalyst used during the reduction process. $\mathrm{GO}$ reduction induces deviations in its structure due to the removal of oxygen and some carbon atoms $[37,38]$. The intensity ratio of the $\mathrm{D}$ band to $\mathrm{G}$ band $\left(\mathrm{I}_{\mathrm{D}} / \mathrm{I}_{\mathrm{G}}\right)$ is commonly used to measure the degree of disordered carbon, as expressed by the $\mathrm{sp}^{3} / \mathrm{sp}^{2}$ carbon ratio. The degradation of crystallinity of graphitic materials is indicated by an increased value of $\mathrm{I}_{\mathrm{D}} / \mathrm{I}_{\mathrm{G}}[19]$. 


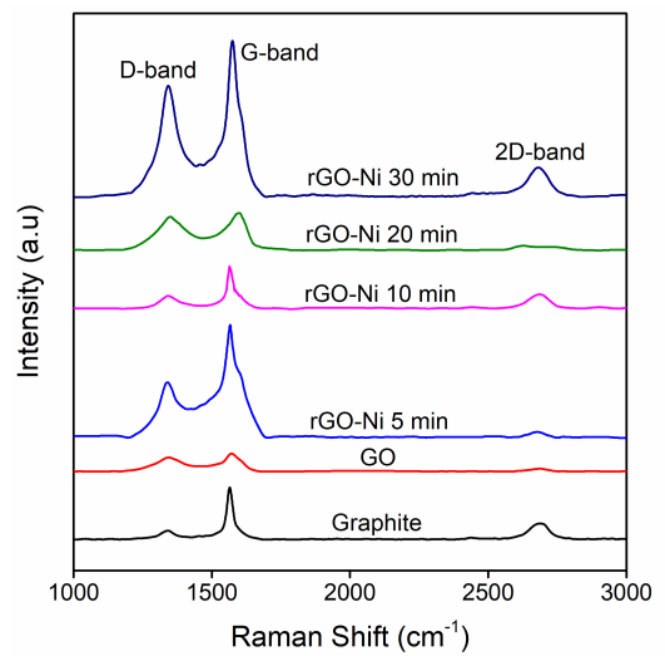

(a)

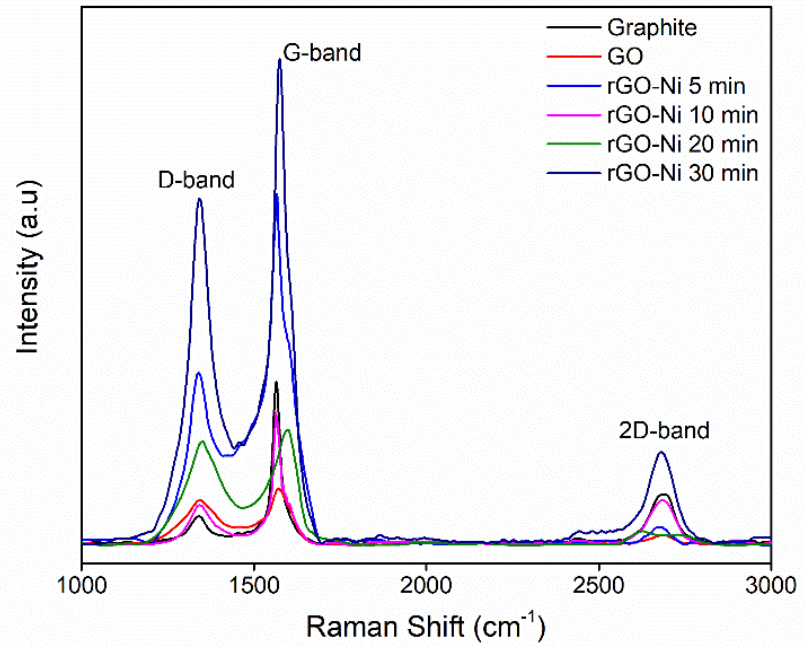

(b)

Figure 4. (a) Raman shift of graphite (G), GO, and rGO-Ni at various reaction times, and (b) their intensities comparison of Raman shift.

Figure 5 shows the multiple-peak-fit Raman spectra of graphite, GO, and rGO-Ni for different reaction times. Figure 5a shows the multiple peak-fit of Raman spectrum of graphite that carried on the D and $\mathrm{G}$ bands. A total of seven peaks could be fit, as shown in Table 1 . The peak at $1339 \mathrm{~cm}^{-1}$ shows the $\mathrm{D}$ band, and the peak at $1565 \mathrm{~cm}^{-1}$ shows the $\mathrm{G}$ band. The peak at $1604 \mathrm{~cm}^{-1}$ is the $\mathrm{D}^{\prime}$ band that makes the $\mathrm{G}$ band broadened. There are three additional peaks $\left(\mathrm{D}^{*}, \mathrm{D}^{* *}, \mathrm{D}^{* * *}\right)$ found at $1263 \mathrm{~cm}^{-1}, 1471 \mathrm{~cm}^{-1}$, and $1518 \mathrm{~cm}^{-1}$, respectively. The $2 \mathrm{D}$ band is found at $2684 \mathrm{~cm}^{-1}$.

Table 1. Decomposition results of graphite.

\begin{tabular}{lcccccc}
\hline \multicolumn{1}{c}{ Peak } & Peak Type & FWHM & Intensity & Center & Area (\%) & $\mathbf{I}_{\mathbf{D}} / \mathbf{I}_{\mathbf{G}}$ \\
\hline $\mathrm{D}^{*}$ & Lorentz & 44.10074 & 2.30117 & 1263.187 & 0.37276 & 0.0055 \\
$\mathrm{D}^{* *}$ & Gauss & 88.18919 & 15.12388 & 1471.11 & 3.38514 & 0.036 \\
$\mathrm{D}^{* * *}$ & Lorentz & 20.34075 & 13.58623 & 1518.833 & 1.02809 & 0.03125 \\
$\mathrm{G}$ & Lorentz & 25.53374 & 416.2986 & 1565.301 & 39.48637 & - \\
$\mathrm{D}^{\prime}$ & Lorentz & 34.40976 & 32.90883 & 1603.995 & 4.19551 & 0.0792 \\
$2 \mathrm{D}$ & Lorentz & 73.10103 & 137.5077 & 2684.201 & 36.03281 & 0.33 \\
\hline
\end{tabular}

Figure $5 b-f$ shows the multiple peak-fit of Raman spectrum of GO and rGO that carried on the D and G bands, and their fitting is presented in Table 2. Figure 5b shows the multiple peak-fit for the Raman spectrum of GO with D and G bands. A total of five peaks were fit, as depicted in the figure. The peak at $1345 \mathrm{~cm}^{-1}$ shows the $\mathrm{D}$ band, and the peak at $1576 \mathrm{~cm}^{-1}$ corresponds to the $\mathrm{G}$ band. There are two additional peaks $\left(\mathrm{D}^{*}, \mathrm{D}^{* *}\right)$ found at $1464 \mathrm{~cm}^{-1}$ and $1507 \mathrm{~cm}^{-1}$, and other peak at $2682 \mathrm{~cm}^{-1}$ represents the $2 \mathrm{D}$ band.

Figure $5 \mathrm{c}$ shows the multiple peak-fit of Raman spectrum of rGO-Ni for 5 min of reaction time. A total of six peaks could be fit as shown. The peak at $1338 \mathrm{~cm}^{-1}$ reveals the $\mathrm{D}$ band, and the peak at $1565 \mathrm{~cm}^{-1}$ signifies the $\mathrm{G}$ band. There are three additional peaks (D*and $D^{* *}$ ) at $1488 \mathrm{~cm}^{-1}$ and $1522 \mathrm{~cm}^{-1}$. The other peak at $1604 \mathrm{~cm}^{-1}$ relates to $\mathrm{D}^{\prime}$ band that makes the $\mathrm{G}$ band broadened. The $2 \mathrm{D}$ band is found at $2682 \mathrm{~cm}^{-1}$. 


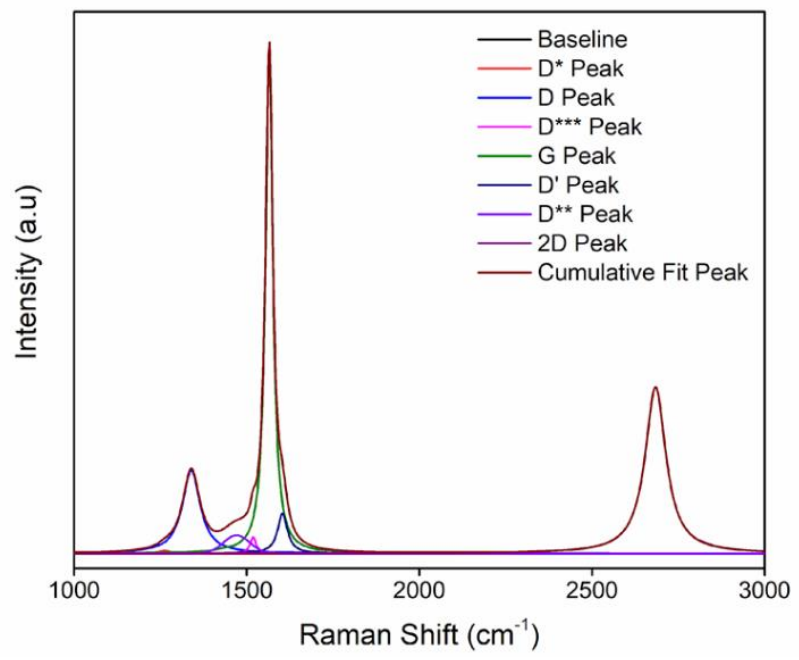

(a)

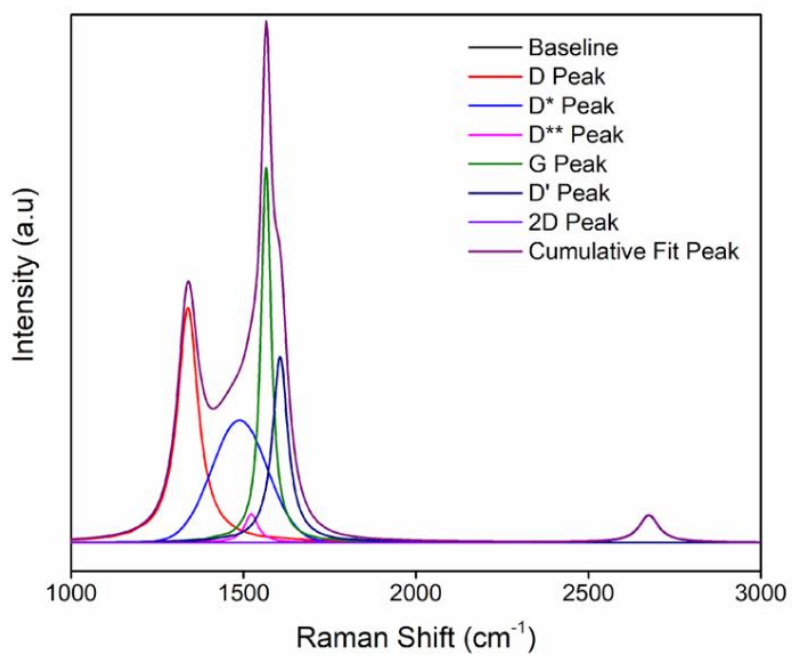

(c)

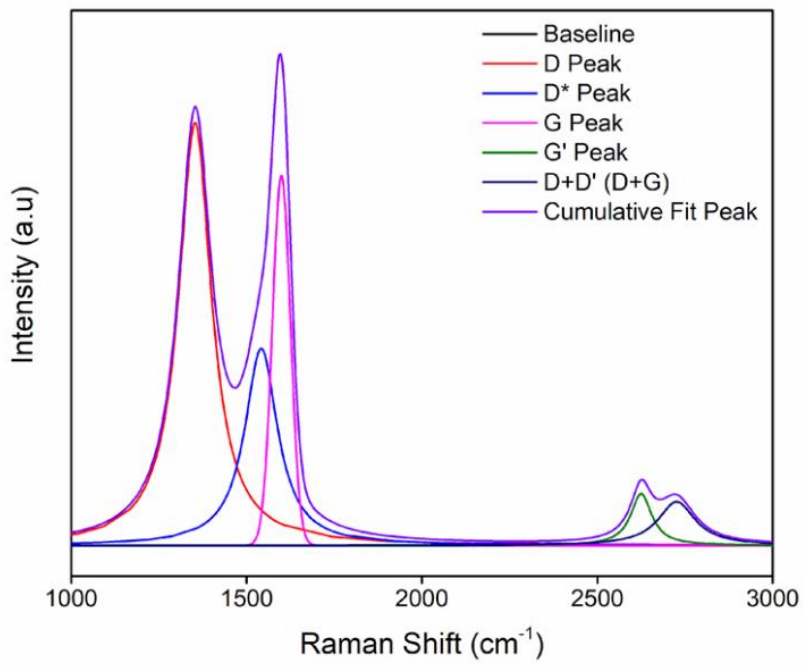

(e)

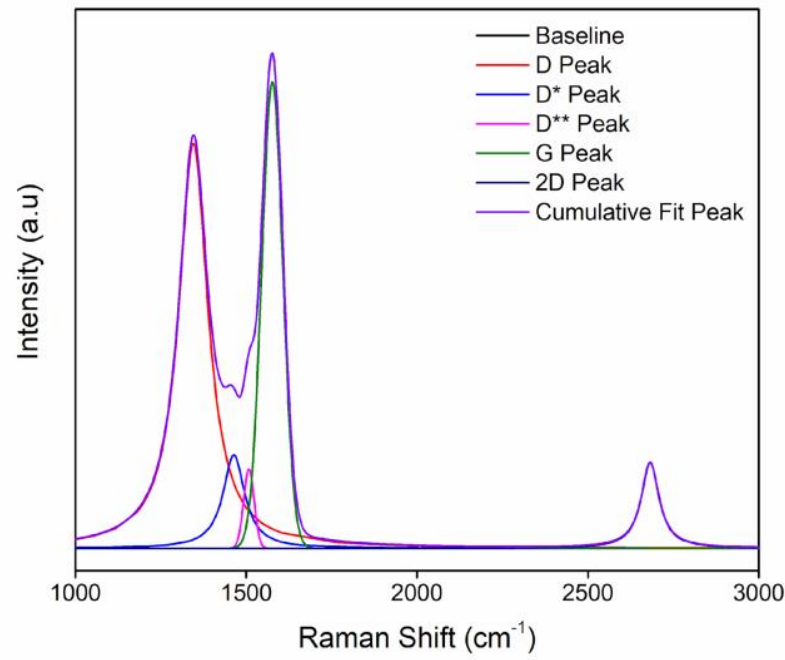

(b)

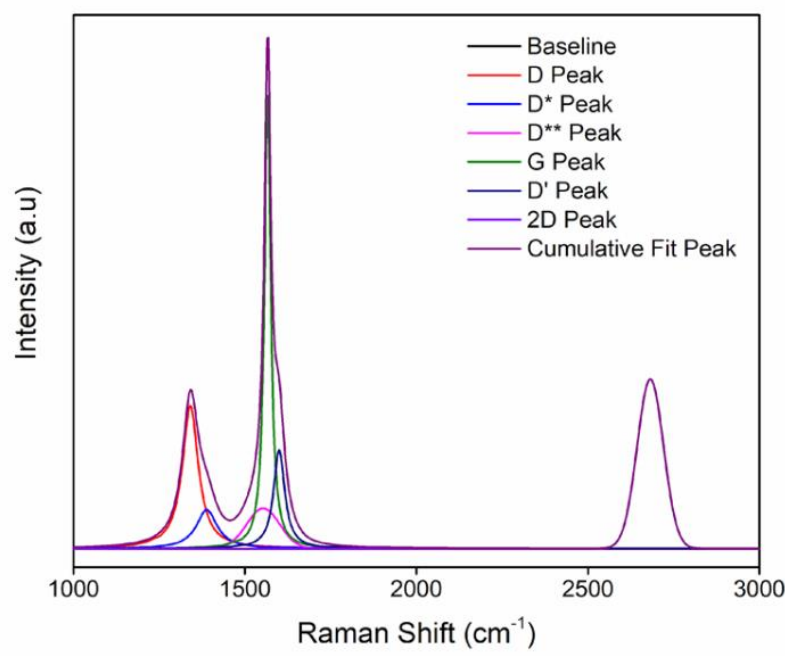

(d)

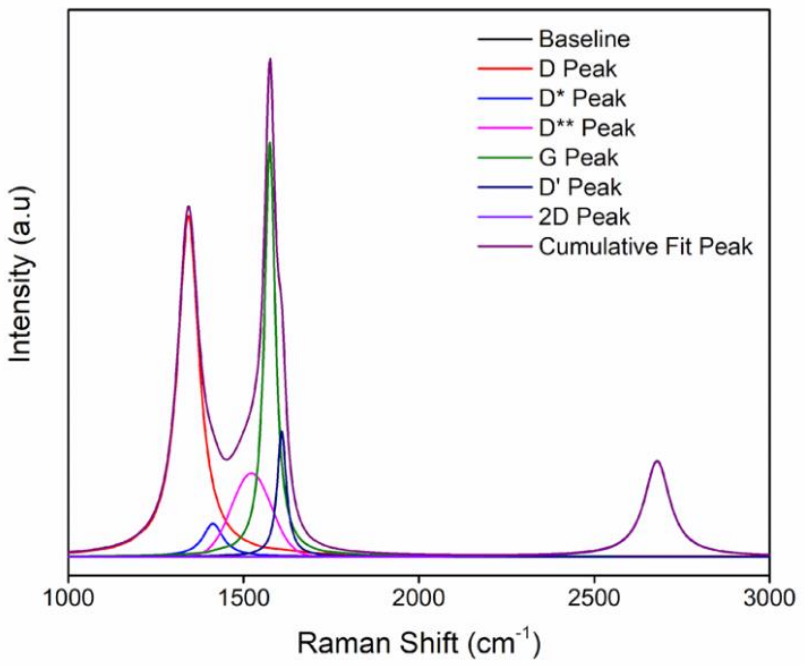

(f)

Figure 5. Multiple peak-fit of Raman spectra of (a) graphite, (b) GO, and rGO-Ni for the reaction time (c) $5 \mathrm{~min}$, (d) $10 \mathrm{~min},(\mathbf{e}) 20 \mathrm{~min}$, and (f) $30 \mathrm{~min}$. 
Figure $5 \mathrm{~d}$ shows the multiple peak-fit Raman spectrum of rGO-Ni for $10 \mathrm{~min}$ of reaction time for the $D$ and $G$ bands. A total of six peaks could be fitted, as shown in the figure. The peak at $1341 \mathrm{~cm}^{-1}$ and at $1566 \mathrm{~cm}^{-1}$ corresponds to the $\mathrm{D}$ and $\mathrm{G}$ band, respectively. There are three additional peaks $\left(D^{*}\right.$ and $\left.D^{* *}\right)$ occurring at $1391 \mathrm{~cm}^{-1}$ and $1546 \mathrm{~cm}^{-1}$. The peak at $1599 \mathrm{~cm}^{-1}$ is the $\mathrm{D}^{\prime}$ band that makes the $\mathrm{G}$ band broadened. The $2 \mathrm{D}$ band is found at $2682 \mathrm{~cm}^{-1}$.

Table 2. Decomposition results of GO and rGO.

\begin{tabular}{|c|c|c|c|c|c|c|c|}
\hline & Peak & Peak Type & FWHM & Intensity & Center & Area (\%) & $\mathrm{I}_{\mathrm{D}} / \mathrm{I}_{\mathrm{G}}$ \\
\hline \multirow{5}{*}{$\mathrm{GO}$} & $\mathrm{D}$ & Lorentz & 103.871 & 111.7583 & 1345.573 & 52.09472 & 0.87 \\
\hline & $\mathrm{D}^{*}$ & Lorentz & 76.86495 & 25.79214 & 1464.012 & 9.02568 & 0.2 \\
\hline & $\mathrm{D}^{* *}$ & Gauss & 36.33935 & 21.84247 & 1507.944 & 2.51529 & 0.17 \\
\hline & $\mathrm{G}$ & Lorentz & 72.56196 & 128.7674 & 1576.557 & 29.60897 & - \\
\hline & $2 \mathrm{D}$ & Lorentz & 63.38208 & 23.66892 & 2682.37 & 6.75535 & 0.18 \\
\hline \multirow{6}{*}{$\begin{array}{l}\mathrm{rGO}-\mathrm{Ni} \\
5 \mathrm{~min}\end{array}$} & $\mathrm{D}$ & Lorentz & 72.36115 & 400.6227 & 1338.942 & 28.3476 & 0.625 \\
\hline & $D^{*}$ & Gauss & 190.0877 & 208.7136 & 1488.591 & 27.05743 & 0.325 \\
\hline & $D^{* *}$ & Lorentz & 47.10426 & 48.40645 & 1522.598 & 2.25922 & 0.075 \\
\hline & $\mathrm{G}$ & Lorentz & 35.12459 & 640.2111 & 1565.578 & 22.37714 & - \\
\hline & $\mathrm{D}^{\prime}$ & Lorentz & 53.94309 & 316.8547 & 1606.357 & 16.91193 & 0.494 \\
\hline & $2 \mathrm{D}$ & Lorentz & 68.07937 & 46.27574 & 2675.5 & 3.04668 & 0.072 \\
\hline \multirow{6}{*}{$\begin{array}{l}\text { rGO-Ni } \\
10 \mathrm{~min}\end{array}$} & $\mathrm{D}$ & Lorentz & 59.55056 & 94.77432 & 1341.33 & 19.9872 & 0.32 \\
\hline & $\mathrm{D}^{*}$ & Lorentz & 77.81392 & 23.73011 & 1391.398 & 6.49989 & 0.078 \\
\hline & $D^{* *}$ & Gauss & 115.7242 & 23.72099 & 1546.179 & 6.81632 & 0.078 \\
\hline & $\mathrm{G}$ & Lorentz & 22.21343 & 296.4301 & 1566.151 & 23.91736 & - \\
\hline & $\mathrm{D}^{\prime}$ & Lorentz & 42.80226 & 68.37753 & 1599.675 & 10.54987 & 0.23 \\
\hline & $2 \mathrm{D}$ & Lorentz & 75.84276 & 121.4737 & 2682.816 & 32.22935 & 0.41 \\
\hline \multirow{5}{*}{$\begin{array}{l}\mathrm{rGO}-\mathrm{Ni} \\
20 \mathrm{~min}\end{array}$} & $\mathrm{D}$ & Lorentz & 114.0963 & 261.4571 & 1353.322 & 50.3196 & 1.144 \\
\hline & $D^{*}$ & Lorentz & 114.0583 & 121.8159 & 1541.898 & 23.60508 & 0.53 \\
\hline & G & Gauss & 60.28815 & 228.7064 & 1599.37 & 16.4825 & - \\
\hline & $G^{\prime}$ & Lorentz & 72.94592 & 32.05832 & 2625.254 & 3.97089 & 0.14 \\
\hline & $\mathrm{D}+\mathrm{D}^{\prime}$ & Lorentz & 128.4541 & 27.1002 & 2726.328 & 5.62193 & 0.118 \\
\hline \multirow{6}{*}{$\begin{array}{l}\text { rGO-Ni } \\
30 \mathrm{~min}\end{array}$} & $\mathrm{D}$ & Lorentz & 72.95094 & 872.99907 & 1342.89959 & 39.75877 & 0.82 \\
\hline & $\mathrm{D}^{*}$ & Lorentz & 69.28206 & 84.36227 & 1412.81349 & 3.66186 & 0.079 \\
\hline & $D^{* *}$ & Gauss & 132.96085 & 213.42246 & 1522.65928 & 12.35659 & 0.2 \\
\hline & $\mathrm{G}$ & Lorentz & 36.67842 & 1061.63651 & 1575.12468 & 24.72983 & - \\
\hline & $\mathrm{D}^{\prime}$ & Lorentz & 31.03816 & 321.42136 & 1608.95909 & 6.34852 & 0.3 \\
\hline & $2 \mathrm{D}$ & Lorentz & 88.23703 & 244.30122 & 2679.46551 & 13.14443 & 0.23 \\
\hline
\end{tabular}

Figure 5e shows the multiple peak-fit of Raman spectrum of rGO-Ni for $20 \mathrm{~min}$ of reaction time for $\mathrm{D}$ and $\mathrm{G}$ bands. A total of five peaks could be fitted as shown. The peak centered at $1341 \mathrm{~cm}^{-1}$ represents the $\mathrm{D}$ band, and the peak centered at $1566 \mathrm{~cm}^{-1}$ corresponds to the $G$ band. There are three additional peaks ( $D^{*}$ and $D^{* *}$ ) occurring at $1391 \mathrm{~cm}^{-1}$ and $1546 \mathrm{~cm}^{-1}$. The peak at $1599 \mathrm{~cm}^{-1}$ is the $\mathrm{D}^{\prime}$ band that leads to the broadening of the $\mathrm{G}$ band. The shape of the 2D band on multiple peak-fit of rGO-Ni for 20 min of reaction time has two peaks rather than a single Lorentzian. The $\mathrm{G}^{\prime}$ peak is found at $2625 \mathrm{~cm}^{-1}$, and the $\mathrm{D}+\mathrm{D}^{\prime}(\mathrm{D}+\mathrm{G})$ peak is found at $2726 \mathrm{~cm}^{-1}$.

Figure $5 \mathrm{f}$ shows the multiple peak-fit Raman spectrum of rGO-Ni for the reaction time of $30 \mathrm{~min}$. A total of six peaks could be fitted as shown. The peak at $1341 \mathrm{~cm}^{-1}$ indicates the presence of the $\mathrm{D}$ band, and the peak at $1566 \mathrm{~cm}^{-1}$ discloses the $\mathrm{G}$ band. There are three additional peaks ( $D^{*}$ and $D^{* *}$ ) that are found at $1391 \mathrm{~cm}^{-1}$ and $1546 \mathrm{~cm}^{-1}$. The peak at $1599 \mathrm{~cm}^{-1}$ is the $\mathrm{D}^{\prime}$ band that makes the $\mathrm{G}$ band broadened. The shape of the $2 \mathrm{D}$ band on multiple peak-fit of rGO-Ni for 20 min of reaction time has two peak profiles rather than a single Lorentzian. The $G^{\prime}$ peak is found at $2625 \mathrm{~cm}^{-1}$, and the $D+D^{\prime}(D+G)$ peak is found at $2726 \mathrm{~cm}^{-1}$. 
In graphite and $\mathrm{rGO}$, the $\mathrm{G}$ band consists of a superposition of two peaks-namely, the $\mathrm{G}$ and $\mathrm{D}^{\prime}$ peaks. The intensity of the $\mathrm{D}^{\prime}$ peak in graphite is proportional to the crystallite size and correlates to the number of defects. For rGO, which has comparatively high defect densities, the $\mathrm{D}^{\prime}$ peak is more intense and thus contributes significantly to the graphene peak. The $D^{\prime}$ peak of graphene samples is diverse from the $G$ peak, but the properties and spectral signature of defective graphene do not close to those of even highly reduced $\mathrm{GO}[34,36]$. In contrast, the highest intensity ratio of $\mathrm{D}$ band to $\mathrm{G}$ band $\left(\mathrm{I}_{\mathrm{D}} / \mathrm{I}_{\mathrm{G}}\right)$ is obtained from the reaction times $20 \mathrm{~min}$ indicated that the degree of oxygen released is higher, compared with other reaction times (Table 2). This result supports the spectra analysis that also finds at $20 \mathrm{~min}$ is the optimal reaction time.

The half-width at half maximum above the graphene centroid position is larger for many GO samples than expected, illustrating that the $G$ band is accompanied by an extra peak at slightly higher energy. By increasing the density of defects, $\mathrm{D}^{\prime}$ modes occur at lower energy around $1580 \mathrm{~cm}^{-1}$, which would theoretically make it appear at lower energy than the $G$ peak. The background of this energy shift of the $D^{\prime}$ mode remains unclear but may depend on the second-nearest force constants. The influence of such a shift on the position and intensity of graphene has not been explored [39]. The origin of the $\mathrm{D}^{*}$, $\mathrm{D}^{* *}$, and $\mathrm{D}^{* * *}$ bands is not clearly understood. Some reports suggest that the $\mathrm{D}^{*}$ peak represents $\mathrm{sp}^{3}$ rich phase of disordered amorphous carbons. The $\mathrm{D}^{* *}$ peak can be caused by the contributions of phonon density of states in finite-size graphitic crystals or by $\mathrm{C}-\mathrm{H}$ vibrations in hydrogenated carbons [40].

\subsection{SEM-EDS}

SEM is used to determine the surface morphology of the material. By characterizing the samples with SEM, the material topography, grain size, and composition of a sample (EDS) can be evidently observed. SEM characterization was carried out for the samples of rGO-Ni, with varying reaction times, and the SEM image of rGO is depicted in Figure 6. The SEM image reveals sheet-like morphology for the various reaction times, and not much difference is observed. The elemental composition of the rGO-Ni with time variations can be seen in Table 3 .

While there is not much information obtained from the SEM micrograph of rGO-Ni for various reaction times, EDS analysis discloses important information about the $\mathrm{C} / \mathrm{O}$ ratio. EDS is one of the ways to determine the success of the oxygen reduction process by observing the difference in the atomic weight of elements present in $\mathrm{rGO}-\mathrm{Ni}$. The $\mathrm{C} / \mathrm{O}$ ratio is high for $10 \mathrm{~min}$ and $20 \mathrm{~min}$ of reaction time, and the percentage of oxygen is relatively low for both the reaction times. Based on other studies, 20 min reaction was considered as optimum. Based on the percentage of composition of the majority of the atoms in Table 3 , it can be observed that the carbon atom represents the main constituent material, and the presence of oxygen atom indicates GO was not completely oxidized. It should be noted that the mass percentage of $\mathrm{Ni}$ and $\mathrm{S}$ present is due to the use of nickel sulfate as a catalyst for the reduction process using microwave irradiation.

Table 3. The EDS of the rGO-Ni.

\begin{tabular}{|c|c|c|c|c|c|c|}
\hline No. & Element & $\begin{array}{c}\text { Before MWI } \\
\text { Atomic \% }\end{array}$ & $\begin{array}{l}5 \text { min. } \\
\text { Atomic \% }\end{array}$ & $\begin{array}{c}10 \mathrm{~min} . \\
\text { Atomic \% }\end{array}$ & $\begin{array}{c}20 \mathrm{~min} . \\
\text { Atomic \% }\end{array}$ & $\begin{array}{c}30 \mathrm{~min} . \\
\text { Atomic \% }\end{array}$ \\
\hline 1 & $C$ & 61.75 & 55.96 & 62.1 & 64.08 & 47.34 \\
\hline 2 & $\mathrm{O}$ & 32.53 & 36.86 & 25.06 & 30.58 & 42.11 \\
\hline 3 & $S$ & 3.99 & 3.7 & 3.76 & 2.67 & 4.03 \\
\hline \multirow[t]{2}{*}{4} & $\mathrm{Ni}$ & 1.73 & 3.49 & 9.06 & 2.67 & 6.51 \\
\hline & $\mathrm{C} / \mathrm{O}$ ratio & 1.89 & 1.52 & 2.48 & 2.10 & 1.12 \\
\hline
\end{tabular}




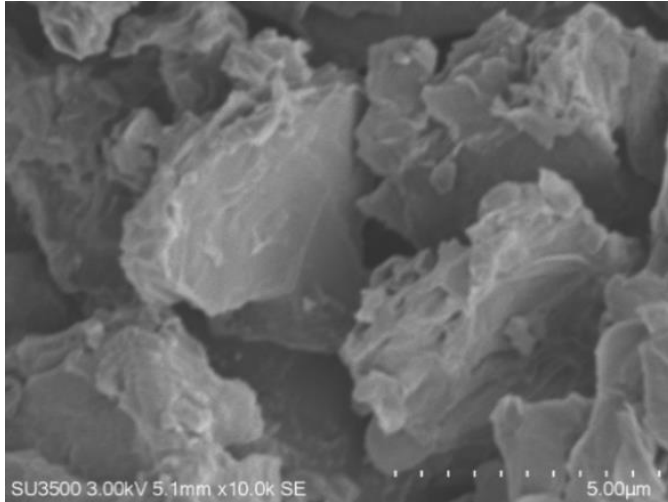

(a)

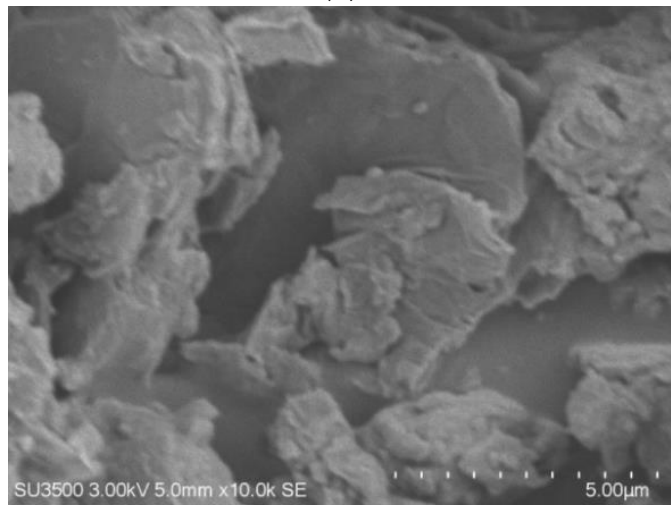

(c)

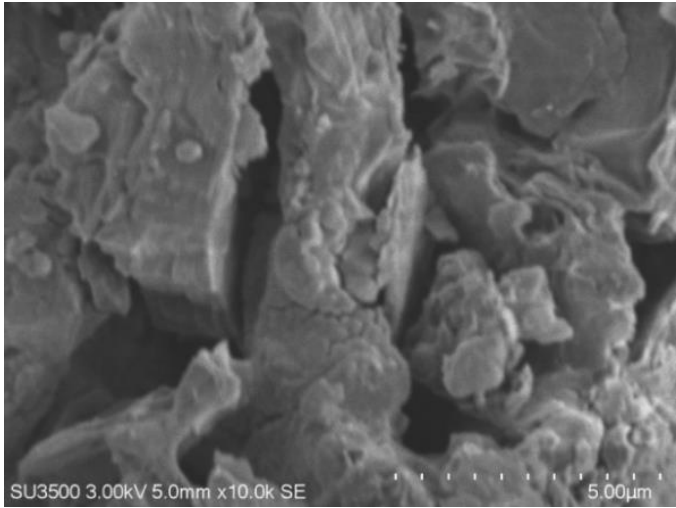

(b)

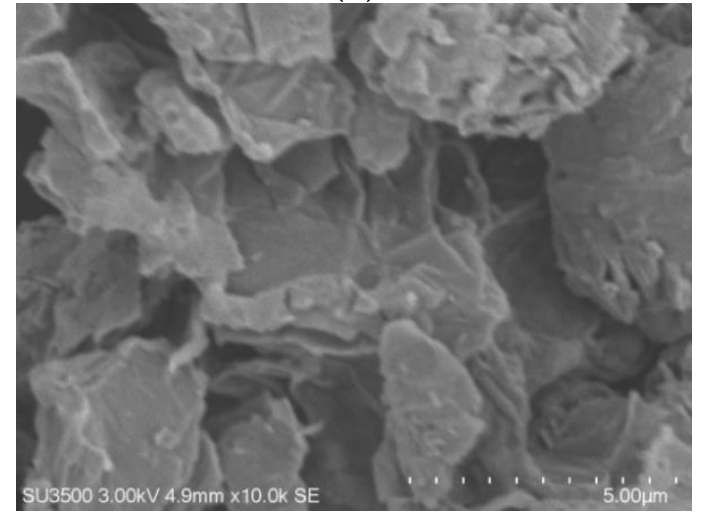

(d)

Figure 6. SEM Morphologies of rGO-Ni for (a) $5 \mathrm{~min}$, (b) $10 \mathrm{~min}$, (c) $20 \mathrm{~min}$, and (d) $30 \mathrm{~min}$ reaction time.

\subsection{Contact Angle}

Figure 7 shows a photograph of the drop of deionized water solution on the graphite, rGO, and rGO-Ni layers deposited onto paint-coated glass. A photograph of a glass-coated only by paint is also shown for comparison. The contact angle of a paint-coated glass is $94.8^{\circ}$, which shows the hydrophobic surface. The contact angle is increased to $118.7^{\circ}$, $150.1^{\circ}$, and $152.6^{\circ}$ when the surface was coated with graphite, rGO, and rGO-Ni, respectively. These results show that the surface changes from hydrophobic to superhydrophobic when it was coated by rGO and rGO-Ni. Moreover, the addition of nickel improves the superhydrophobicity of the painted glass, which might be caused by the surface roughness and hierarchical nanostructures or periodic spike structure of the surface.
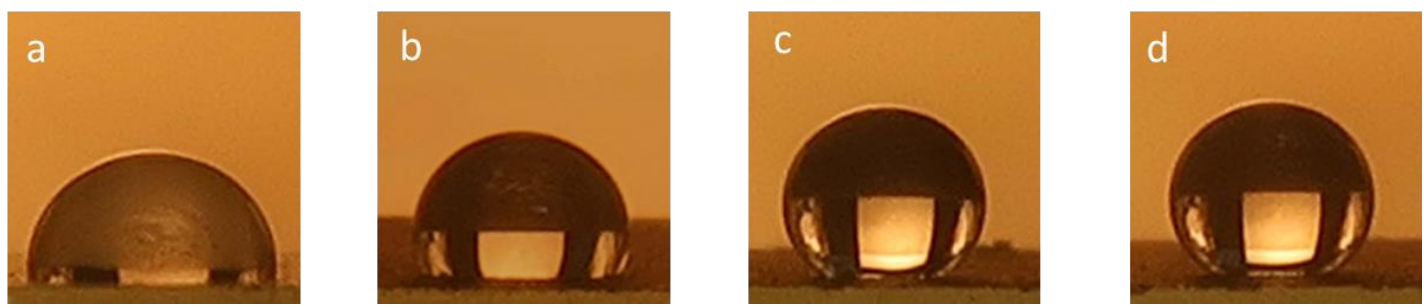

Figure 7. Photographs of DI water drop onto (a) painted glass, (b) graphite coated on painted glass, (c) rGO coated on painted glass, and (d) rGO-Ni coated on painted glass. The contact angle values of (a-d) are $94.8^{\circ}, 118.7^{\circ}, 150.1^{\circ}$, and $152.6^{\circ}$, respectively. 


\subsection{AFM}

Surface images of painted glass coated by graphite, $\mathrm{rGO}, \mathrm{rGO}-\mathrm{Ni}$, and painted glass only are shown in Figure 8. We scanned the surface of the films to obtain the surface roughness, indicated by the value of $R_{q}$ (root mean square roughness) and Ra (average roughness). $R_{q}$ is the root of the average square of the surface roughness level, while the value of $\mathrm{Ra}$ is the arithmetic mean of the surface height. The values were obtained from the difference in height at several positions, compared with the arithmetic average from the surface [41]. The $\mathrm{R}_{\mathrm{q}}$ values of painted samples without binder, coated by graphite, $\mathrm{rGO}$, and rGO-Ni are $6.923 \mathrm{~nm}, 2.240 \mathrm{~nm}, 19.745 \mathrm{~nm}$, and $2.147 \mathrm{~nm}$, respectively. Meanwhile, the values of Ra are $5.411 \mathrm{~nm}, 1.815 \mathrm{~nm}, 11.109 \mathrm{~nm}$, and $1.348 \mathrm{~nm}$ for painted samples without binder, coated by graphite, rGO, and rGO-Ni, respectively.

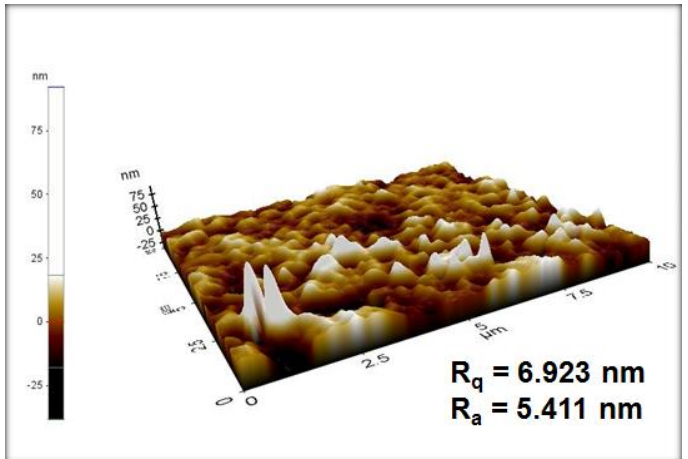

(a)

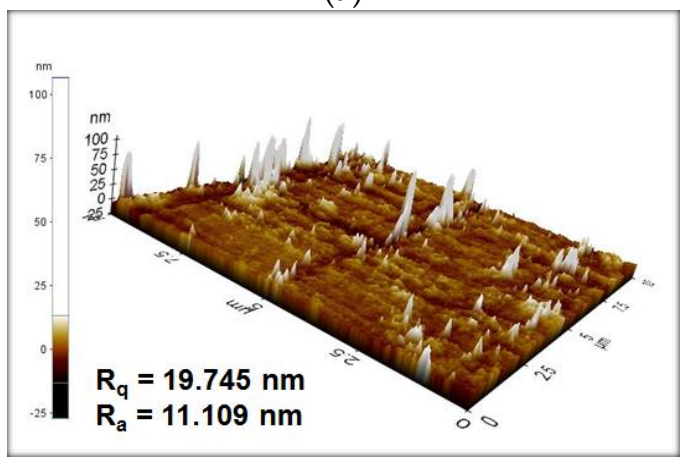

(c)

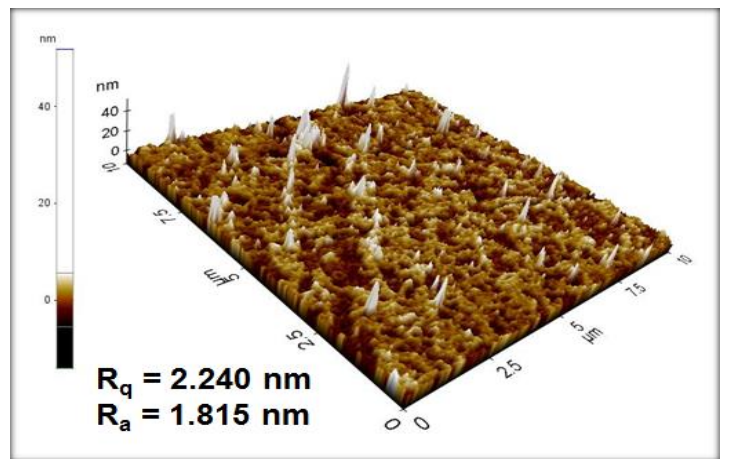

(b)

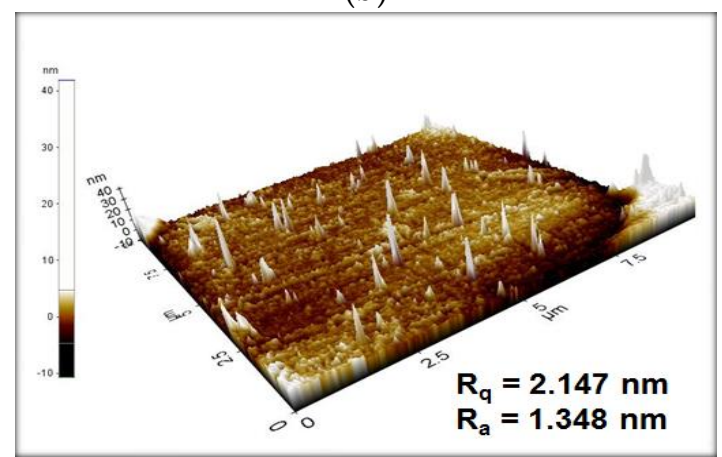

(d)

Figure 8. AFM images of the film surface (a) painted glass, (b) graphite coated on painted glass, (c) rGO coated on painted glass, and (d) rGO-Ni coated on painted glass. The surface roughness values of all films are inserted.

Surface roughness-induced superhydrophobicity has been intensively studied in terms of the lotus effect, where the hydrophobicity properties of the surface can be increased by increasing the roughness of the surface [42,43]. Lotus leaves have hierarchical micro/nanoscale structures, where water on such a surface forms a spherical droplet and significantly reduces the contact area and interaction between water and the surface or adhesion to the surface [44]. Both theoretical models and experimental studies have been carried out to determine the effect of surface roughness on surface wettability, which is represented by contact angle value [25,45-47]. Wenzel and Cassie-Baxter models are mostly used to describe and predict the contact angle on rough surfaces. The Wenzel model uses a homogeneous interface that considers a water droplet that seeps in between the irregularities of a rough surface. The Cassie-Baxter model considers a water droplet that sits on top of the irregularities and forms a layer trapped between the irregularities beneath it, leading to a composite solid-liquid-air interface. In the Wenzel model, the contact angle of the rough surface increases with increasing surface roughness, which is defined as the ratio of the solid-liquid area to its projection on a flat plane [48]. In the 
Cassie-Baxter model, the contact angle depends on the surface roughness, but also on the fractional flat geometric area of the liquid-air interfaces under the droplet or air pockets. These air pockets underneath the liquid will reduce the contact area between water/liquid and surface, therefore increasing the contact angle. Periodic structures such as pillars or cones or spikes in micro- or nanometers size are commonly fabricated on the surface to improve the CA [49].

The AFM image of the painted glass in Figure 8a shows a rough surface, which causes the hydrophobic surface with the CA value of $94.8^{\circ}$, as described both using Wenzel and Cassie-Baxter models. Graphite deposition on painted glass produces nanostructures or pillars or spikes with a height of less than $40 \mathrm{~nm}$, which are almost uniformly distributed, as shown in Figure 8b. These nano-spikes increases numbers of air pocket formation that reduces the contact area between water and surface, as described by the Cassie-Baxter model. As a consequence, the CA value is increased to $118.7^{\circ}$. The height of these spikes is increased when rGO is deposited on the painted glass, as shown in the AFM image in Figure 8c. As a result, the surface becomes superhydrophobic, as indicated by the CA of $150.1^{\circ}$. Nickel doping on rGO (rGO-Ni) produces spikes that are more evenly distributed or a periodic spike structure on the surface, as shown in Figure 8d, thereby increasing the contact angle value to $152.6^{\circ}$. Our study shows that the superhydrophobic surface of the sample can be prepared by deposition of nickel-doped rGO (rGO-Ni) using a simple spray technique, which is a more practical use for large-area coating of the surface and, therefore, more favorable for the industry.

\section{Conclusions}

In this study, GO was treated with nickel sulfate catalyst under $\mathrm{Ar} / \mathrm{H}_{2}$, in the ratio of 4:1, by microwave irradiation method. The role of $\mathrm{Ar}$ and $\mathrm{H}_{2}$ is to bind the oxygen within the system. FTIR analysis was performed to determine the reduction of GO to rGO, using nickel sulfate as a catalyst. Based on the analysis, the reaction time of $20 \mathrm{~min}$ in $\mathrm{Ar} / \mathrm{H}_{2}$ atmosphere with a flow rate of $0.4 \mathrm{~L} / \mathrm{min}$, microwave power of $720 \mathrm{~W}$, and the sample mass of $0.5 \mathrm{~g}$ was optimal. The reduction of GO to $\mathrm{rGO}$ was also reiterated by XRD studies. Raman spectroscopic analysis and peak fitting were performed for graphite, GO, rGO, and rGO-Ni with various reaction times $(5,10,15,20$, and $30 \mathrm{~min})$. The SEM analysis reveals sheet-like morphology for the prepared rGO-Ni at various reaction times, and EDS results illustrate $20 \mathrm{~min}$ reaction time leads to a better reduction of GO to $\mathrm{rGO}$.

As prepared, rGO-coated composite confirms its own superhydrophobic nature, and interestingly, the additional rGO-Ni-coated sample resulted in increasing superhydrophobicity. Thus, the presence of Ni created spikes more evenly distributed or periodic spikes on the surface, providing unique interaction with water droplets to form superhydrophobic surfaces.

Author Contributions: Conceptualization, I.M.J. and A.B.; methodology, A.B., M.S.H., F.F., V.M. and C.P.; validation, I.M.J., A.B. and C.P.; writing—original draft preparation, A.B.; writing-review and editing, I.M.J.; funding acquisition, I.M.J. All authors have read and agreed to the published version of the manuscript.

Funding: The authors acknowledge that this research is partially funded by the Academic Leadership Grant (ALG) of Universitas Padjadjaran with contract no 1959/UN6.3.1/PT.00/2021, Bandung, Indonesia; this research is also partially funded by the Indonesian Ministry of Research and Technology/National Agency for Research and Innovation, and the Indonesian Ministry of Education and Culture, Under World Class University Program managed by Institut Teknologi Bandung.

Institutional Review Board Statement: Not applicable.

Informed Consent Statement: Not applicable.

Data Availability Statement: The data presented in this study are available on request from the corresponding author.

Conflicts of Interest: The authors declare no conflict of interest. 


\section{References}

1. Geim, A.K. Graphene: Status and prospects. Science 2019, 324, 1530-1534. [CrossRef]

2. Strankowski, M.; Bodarczyk, D.; Piszczyk, A.; Strankowska, J. Polyurethane nanocomposites containing reduced graphene oxide, FTIR, Raman, and XRD studies. J. Spectrosc. 2016, 2016, 7520741. [CrossRef]

3. Wang, Y.; Zhao, Y.; Bao, T.; Li, X.; Su, Y.; Duan, Y. Preparation of Ni-reduced graphene oxide nanocomposites by Pd-activated electroless deposition and their magnetic properties. Appl. Surf. Sci. 2012, 258, 8603-8608. [CrossRef]

4. Antolini, E. Graphene as a new carbon support for low-temperature fuel cell catalysts. Appl. Catal. B Environ. 2012, 123-124, 52-68. [CrossRef]

5. $\quad$ Singh, B.P.; Nayak, S.; Nanda, K.K.; Jena, B.K.; Bhattacharjee, S.; Besra, L. The production of a corrosion resistant graphene reinforced composite coating on copper by electrophoretic deposition. Carbon 2013, 614, 7-56. [CrossRef]

6. Liu, Y.; Zhang, J.; Li, S.; Wang, Y.; Han, Z.; Ren, L. Fabrication of a superhydrophobic graphene surface with excellent mechanical abrasion and corrosion resistance on an aluminum alloy substrate. RSC Adv. 2014, 4, 45389-45396. [CrossRef]

7. Wang, J.-N.; Zhang, Y.-L.; Liu, Y.; Zheng, W.; Lee, L.P.; Sun, H.-B. Recent developments in superhydrophobic graphene and graphene-related materials: From preparation to potential applications. Nanoscale 2015, 7, 7101-7114. [CrossRef]

8. Kiran, N.U.; Dey, S.; Singh, B.P.; Besra, L. Graphene coating on copper by electrophoretic deposition for corrosion prevention. Coatings 2017, 7, 214. [CrossRef]

9. Nine, M.J.; Cole, M.A.; Johnson, L.; Tran, D.N.H.; Losic, D. Robust superhydrophobic graphene-based composite coatings with self-cleaning and corrosion barrier properties. ACS Appl. Mater. Interfaces 2015, 7, 28482-28493. [CrossRef]

10. Jishnu, A.; Jayan, J.S.; Saritha, A.; Sethulekshmi, A.S.; Venu, G. Superhydrophobic graphene-based materials with self-cleaning and anticorrosion performance: An appraisal of neoteric advancement and future perspectives. Colloids Surf. A Physicochem. Eng. Asp. 2020, 606, 125395.

11. Pei, S.; Cheng, H.-M. The reduction of graphene oxide. Carbon 2012, 50, 3210-3228. [CrossRef]

12. Miao, C.; Zheng, C.; Liang, O.; Xie, Y.-H. Chemical Vapor Deposition of Graphene. In Physics and Applications of Graphene; Mikhailov, S., Ed.; InTech Europe: Rijeka, Croatia, 2011; pp. 37-54.

13. Paulchamy, B.; Arthi, G.; Lignesh, B.D. A simple approach to stepwise synthesis of graphene oxide nanomaterial. J. Nanomed. Nanotechnol. 2015, 6, 253.

14. Kim, T.; Jo, C.; Lim, W.G.; Lee, J.; Lee, J.; Lee, K.H. Facile conversion of activated carbon to battery anode material using microwave graphitization. Carbon 2016, 104, 106-111. [CrossRef]

15. Kim, T.; Lee, J.; Lee, K.-H. Full graphitization of amorphous carbon by microwave heating. RSC Adv. 2016, 6, 24667-24674. [CrossRef]

16. Sevilla, M.; Fuertes, A.B. Catalytic graphitization of templated mesoporous carbons. Carbon 2006, 44, 468-474. [CrossRef]

17. Zou, L.; Huang, B.; Huang, Y.; Huang, Q.; Wang, C. An investigation of heterogeneity of the degree of graphitization in carbon-carbon composites. Mater. Chem. Phys. 2003, 82, 654-662. [CrossRef]

18. Chu, P.K.; Li, L. Characterization of amorphous and nanocrystalline carbon films. Mater. Chem. Phys. 2006, 96, 253-277. [CrossRef]

19. Khai, T.V.; Kwak, D.S.; Kwon, Y.J.; Kim, S.S.; Shim, K.B.; Kim, H.W. High-quality graphene thin films synthesized by $\mathrm{H}_{2}$ ambient-annealing of reduced graphene oxide sheets. J. Ceram. Process. Res. 2013, 14, 355-362.

20. Chen, W.; Yan, L.; Bangal, P.R. Preparation of graphene by the rapid and mild thermal reduction of graphene oxide induced by microwaves. Carbon 2010, 48, 1146-1152. [CrossRef]

21. Joni, I.M.; Hardiati, M.S.; Faizal, F.; Panatarani, C. Synthesis of rGO-Ni by microwave irradiation method. AIP Conf. Proc. 2020, $2219,080019$.

22. Jeevahan, J.; Chandrasekaran, M.; Joseph, G.B.; Durairaj, R.B.; Mageshwaran, G. Superhydrophobic surfaces: A review on fundamentals, applications, and challenges. J. Coat. Technol. Res. 2018, 15, 231-250. [CrossRef]

23. Jin, M.; Xing, Q.; Chen, Z. A Review: Natural superhydrophobic surfaces and applications. J. Biomater. Nanobiotechnol. 2020, 11, 110-149. [CrossRef]

24. Liravi, M.; Pakzad, H.; Moosavi, A.; Nouri-Borujerdi, A. A comprehensive review on recent advances in superhydrophobic surfaces and their applications for drag reduction. Prog. Org. Coat. 2020, 140, 105537. [CrossRef]

25. Yan, Y.Y.; Gao, N.; Barthlott, W. Mimicking natural superhydrophobic surfaces and grasping the wetting process: A review on recent progress in preparing superhydrophobic surfaces. Adv. Colloid Interface Sci. 2011, 169, 80-105. [CrossRef]

26. Wei, D.W.; Wei, H.; Gauthier, A.C.; Song, J.; Jin, Y.; Xiao, H. Superhydrophobic modification of cellulose and cotton textiles: Methodologies and applications. J. Bioresour. Bioprod. 2020, 5, 1-15. [CrossRef]

27. Guan, F.; Song, Z.; Xin, F.; Wang, H.; Yu, D.; Li, G.; Liu, W. Preparation of hydrophobic transparent paper via using polydimethylsiloxane as transparent agent. J. Bioresour. Bioprod. 2020, 5, 37-43. [CrossRef]

28. Esmailzadeh, S.; Khorsand, S.; Raeissi, K.; Ashrafizadeh, F. Microstructural evolution and corrosion resistance of superhydrophobic electrodeposited nickel films. Surf. Coat. Technol. 2015, 283, 337-346. [CrossRef]

29. Ding, S.B.; Xiang, T.F.; Li, C.; Zheng, S.L.; Wang, J.; Zhang, M.X.; Dong, C.D.; Chan, W.M. Fabrication of self-cleaning superhydrophobic nickel/graphene hybrid film with improved corrosion resistance on mild steel. Mater. Des. 2017, 117, 280-288. [CrossRef]

30. Bai, Z.; Zhang, B. Fabrication of superhydrophobic reduced-graphene oxide/nickel coating with mechanical durability, selfcleaning and anticorrosion performance. Nano Mater. Sci. 2020, 2, 151-158. [CrossRef] 
31. Schneider, L.; Laustsen, M.; Mandsberg, N.; Taboryski, R. The Influence of structure heights and opening angles of micro- and nanocones on the macroscopic surface wetting properties. Sci. Rep. 2016, 6, 21400. [CrossRef]

32. Hummers, W.S.; Offeman, R.E. Preparation of graphitic oxide. J. Am. Chem. Soc. 1958, 80, 1339. [CrossRef]

33. Joni, I.M.; Vanitha, M.; Camellia, P.; Balasubramanian, N. Augmentation of graphite purity from mineral resources and enhancing \% graphitization using microwave irradiation: XRD and Raman studies. Diam. Relat. Mater. 2018, 88, 129-136.

34. Zhu, Y.; Murali, S.; Stoller, M.D.; Velamakanni, A.; Piner, R.D.; Ruoff, R.S. Microwave assisted exfoliation and reduction of graphite oxide for ultracapacitors. Carbon 2010, 48, 2118-2122. [CrossRef]

35. Lu, M.; Gao, N.; Zhang, X.J.; Wang, G.S. Reduced graphene oxide decorated with octahedral NiS 2 /NiS nanocrystals: Facile synthesis and tunable high frequency attenuation. RSC Adv. 2019, 9, 5550-5556. [CrossRef]

36. Muthukannan, V.; Praveen, K.; Natesan, B. Fabrication and characterization of magnetite/reduced graphene oxide composite incurred from iron ore tailings for high performance application. Mater. Chem. Phys. 2015, 162, 400-407. [CrossRef]

37. Sundaram, R.S. Chemically Derived Graphene. In Graphene: Properties, Preparation, Characterisation and Devices, 2nd ed.; Skakalova, V., Kaiser, A.B., Eds.; Woodhead Publishing: Duxford, UK, 2014; pp. 50-80.

38. Dinh, D.A.; Hui, K.S.; Hui, K.N.; Cho, Y.R.; Zhou, W.; Hong, X.; Chun, H.-H. Green synthesis of high conductivity silver nanoparticle-reduced graphene oxide composite films. Appl. Surf. Sci. 2014, 298, 62-67. [CrossRef]

39. Alice, A.K.; Benjamin, R.; Tamara, L.; Andrew, T.; Joselito, M.; Andrew, I.A.; King, A.A.K.; Davies, B.R.; Noorbehesht, N.; Newman, P. A new Raman metric for the characterisation of graphene oxide and its derivatives. Sci. Rep. 2016, 6, 19491.

40. Wang, G.; Bai, J.; Wang, Y.; Ren, Z.; Bai, J. Preparation and electrochemical performance of a cerium oxide-graphene nanocomposite as the anode material of a lithium ion battery. Scr. Mater. 2011, 65, 339-342. [CrossRef]

41. De Oliveira, R.R.L.; Albuquerque, D.A.C.; Cruz, T.G.S.; Yamaji, F.M.; Leite, F.L. Measurement of the Nanoscale Roughness by Atomic Force Microscopy: Basic Principles and Applications. In Atomic Force Microscopy Imaging, Measuring and Manipulating Surfaces at the Atomic Scale; Bellitto, V., Ed.; InTech Europe: Rijeka, Croatia, 2012; pp. 147-174.

42. Yun, X.; Xiong, Z.; He, Y.; Wang, X. Superhydrophobic lotus-leaf-like surface made from reduced graphene oxide through softlithographic duplication. RSC Adv. 2020, 10, 5478-5486. [CrossRef]

43. Cho, Y.; Park, C.H. Objective quantification of surface roughness parameters affecting superhydrophobicity. RSC Adv. 2020, 10, 31251-31260. [CrossRef]

44. Yamamoto, M.; Nishikawa, N.; Mayama, H.; Nonomura, Y.; Yokojima, S.; Nakamura, S.; Uchida, K. Theoretical explanation of the lotus effect: Superhydrophobic property changes by removal of nanostructures from the surface of a lotus leaf. Langmuir 2015, 31, 7355-7363. [CrossRef] [PubMed]

45. Spori, D.M.; Drobek, T.; Zürcher, S.; Ochsner, M.; Sprecher, C.; Mühlebach, A.; Spencer, N.D. Beyond the lotus effect: Roughness influences on wetting over a wide surface-energy range. Langmuir 2008, 24, 5411-5417. [CrossRef]

46. Nosonovsky, M.; Bhushan, B. Roughness-induced superhydrophobicity: A way to design non-adhesive surfaces. J. Phys. Condens. Matter 2008, 20, 225009. [CrossRef]

47. Koch, K.; Bhushan, B.; Jung, Y.C.; Barthlott, W. Fabrication of artificial Lotus leaves and significance of hierarchical structure for superhydrophobicity and low adhesion. Soft Matter 2009, 5, 1386-1393. [CrossRef]

48. Nosonovsky, M.; Bhushan, B. Hierarchical roughness makes superhydrophobic surfaces stable. Microelectron. Eng. 2007, $84,382-386$

49. Bhushan, B.; Jung, Y.C.; Koch, K. Micro-, nano- and hierarchical structures for superhydrophobicity, self-cleaning and low adhesion. Philos. Trans. R. Soc. A 2009, 367, 1631-1672. [CrossRef] [PubMed] 